\title{
A structural equation analysis on the relationship between maternal health services utilization and newborn health outcomes: a cross-sectional study in Eastern Uganda
}

Rornald Muhumuza Kananura ${ }^{1,2,5^{*}}$, Robert Wamala², Elizabeth Ekirapa-Kiracho ${ }^{1}$, Moses Tetui ${ }^{1,3}$, Suzanne N. Kiwanuka ${ }^{1}$, Peter Waiswa ${ }^{1,4,5}$ and Leonard K. Atuhaire ${ }^{2}$

\begin{abstract}
Background: Neonatal and maternal health services have a bearing on neonatal mortality. Direct and indirect factors affecting neonatal health outcomes therefore require understanding to enable well-targeted interventions. This study, therefore, assessed the interrelationship between newborn health outcomes and maternal service utilization factors.

Methods: We investigated maternal health utilization factors using health facility delivery and at least four Antenatal Care (ANC) visits; and newborn health outcomes using newborn death and low birth weight (LBW). We used data from a household cross-sectional survey that was conducted in 2015 in Kamuli, Pallisa and Kibuku districts. We interviewed 1946 women who had delivered in the last 12 months. The four interrelated (Endogenous) outcomes were ANC attendance, health facility delivery, newborn death, and LBW. We performed analysis using a structural equation modeling technique.

Results: A history of newborn death $(\mathrm{aOR}=12.64,95 \% \mathrm{Cl} 5.31-30.10)$ and birth of a $\mathrm{LBW}$ baby $(\mathrm{aOR}=3.51,95 \% \mathrm{Cl} 1$. 48-8.37) were directly related to increased odds of newborn death. Factors that reduced the odds of LBW as a mediating factor for newborn death were ANC fourth time attendance ( $a \mathrm{OR}=0.62,95 \% \mathrm{Cl} 0.45-0.85$ ), having post-primary level education $(\mathrm{aOR}=0.68,95 \% \mathrm{Cl} 0.46-0.98)$ compared to none and being gravida three ( $\mathrm{aOR}=0.49,95 \% \mathrm{Cl} 0.26-0.94$ ) compared to being gravida one. Mother's age group, 20-24 (aOR=0.24, $95 \% \mathrm{Cl} 0.08-0.75)$ and $25-29$ years $(\mathrm{aOR}=0.20,95 \% \mathrm{Cl} 0.05-0.86)$ compared to $15-19$ years was also associated with reduced odds of LBW. Additionally, ANC visits during the first trimester (aOR=2.04, 95\% Cl 1. 79-2.34), and village health teams (VHTs) visits while pregnant (aOR $=1.14,95 \% \mathrm{Cl} 1.01-1.30)$ were associated with increased odds of at least four ANC visits, which is a mediating factor for health facility delivery, LBW and newborn death. Surprisingly, newborn death was not significantly different between health facility and community deliveries.

(Continued on next page)
\end{abstract}

\footnotetext{
*Correspondence: mk.rornald@yahoo.com; mk.rornald@musph.ac.ug

${ }^{1}$ Makerere University School of Public Health (MakSPH), Makerere University

College of Health Sciences, Kampala, Uganda

${ }^{2}$ Department of Planning and Applied Statistics, Makerere University School

of Statistics and Planning, Kampala, Uganda

Full list of author information is available at the end of the article
} 
(Continued from previous page)

Conclusions: Attending ANC at least four times was a mediating factor for reduced newborn death and low birth weight. Interventions in maternal health and newborn health should focus on factors that increase ANC fourth time attendance and those that reduce LBW especially in resource-limited settings. Targeting women with high-risk pregnancies is also crucial for reducing newborn deaths.

Keywords: Interrelationship, Structural equation modeling, Maternal health utilization, Newborn outcomes,

\section{Background}

Globally, at least four million newborns die within four weeks of life every year, of which $75 \%$ die within the first week [1]. The largest proportion of neonatal death occurs in low-and-middle-income countries (LMICs) where access to quality health care is low $[1,2]$. Most of these newborns die without skilled care that could greatly increase their chances of survival [3]. Access to quality maternal and newborn health services in most of the LMCs is constrained due to various health systems, cultural, socioeconomic, and demographic factors [3]. Though the preventable causes of newborn death such as congenital malformations, tetanus, preterm delivery, diarrhea, pneumonia, intrapartum-related birth asphyxia, and consequences of LBW are well known [1, 4-7], addressing such causes becomes impossible in LMICs where health facilities always experience lack of skilled health workers and stock out of essential medicine and supplies $[8,9]$.

Uganda's neonatal death rate is estimated at 27 per 1000 live births, which is higher than that of her neighbors (Kenya at 23 and Tanzania at 21 per 1000 live births) [2]. A wider comparison with other African countries still finds Uganda's rate high; for example, Egypt has a rate of 11, South Africa, 15 and Morocco 17 deaths per 1000 live births according to a recent UNICEF report on child health outcomes [2]. Low birth weight (LBW) in Uganda is roughly estimated at $11 \%$ [10] given that almost a quarter of the newborns are not weighted [11]. LBW has been found to be significantly related to newborn deaths especially in resource-limited settings $[4,11,12]$; yet these could be saved with simple care such as warmth, feeding, hygiene and early treatment of infection $[4,6]$.

In addition, the utilization of maternal and newborn services such as ANC attendance, skilled delivery assistance, and postnatal care in Uganda is still below average. For example, ANC fourth time attendance, delivery under skilled assistance and postnatal care within 2 days are estimated at 48,58 , and $33 \%$ respectively [13]. Yet these services are cornerstones for assessing newborn and maternal danger signs during pregnancy, labor and after delivery $[3,6]$. The utilization of these services is challenged by both demand and supply side constraints including; delays to seek care and system inefficiencies such as low staffing levels, poor care skills, frequent supplies and drugs stock outs and the lack of essential equipment [5]. On the demand side, access to finances has been indicated as the most important factor that affects the utilization of maternal and newborn services [14-16]. Studies done in Rwanda and Ghana have indicated the importance of insurance schemes in increasing the likelihood of maternal and newborn skilled service utilization $[15,16]$. Women's access to and control over finances, not only guarantees timely access to services, but also to quality services $[15,16]$. In Uganda, it is common for women to deliver at home or within the community because of inhibiting transport costs related to poor community transport systems $[17,18]$. Increasing newborn survival, therefore, needs a continuum of care that addresses both the demand and supply side bottlenecks.

The predictors for newborn health outcomes (NHO) and maternal health care utilization (MHCU) are always determined based on approaches that assume direct associations rather than indirect factors $[12,19]$. In this study, we considered newborn death (newborn died within 28 days after delivery) and LBW (newborn weight $<2.5 \mathrm{Kg}$ ) for NHOs, while for $\mathrm{MHCU}$, we considered health facility delivery and ANC fourth time attendance. We sought therefore to breach this gap by exploring the interrelationship between factors for newborn outcomes and factors for health facility utilization in rural communities. We believe that health planners, policymakers, and other stakeholders especially from similar settings can use our findings to inform and guide policy formulation needed for the design of interventions aimed at achieving sustainable development goal three. In addition, our findings may contribute to the existing literature particularly on understanding the complexities around newborn death and its relations to low birth weight, health facility delivery, and ANC attendance.

\section{Methods}

\section{Study design and population}

Data for this study was from the end-line cross-sectional survey conducted by Makerere University School of Public Health in July/August 2015 for the evaluation of a Maternal and Neonatal Implementation for Equitable Systems (MANIFEST) project, which was a quasiexprimental study implemented in the districts of Pallisa, Kibuku and Kamuli in Eastern Uganda from 2013-2015. The project aim was to improve maternal and neonatal health outcomes. The whole of Kibuku district was an 
intervention area because it only had one health subdistrict. Kamuli and Pallisa had three health sub-districts (HSD), and so one HSD was selected as an intervention area and another as a comparison area in each of the district. The district team did the selection of the intervention and comparison area, which was purposively based on the district maternal and new-born service indicators. Data was collected from women who had delivered in the last 12 months irrespective of birth outcomes. The estimated population in the three districts is $1,106,100$ [20].

\section{Sample size and selection of study participants}

The study sample size was determined using a two-sided Z-test of the difference between proportions with $80 \%$ statistical power, a $5 \%$ significance level and 1.5 design effect that resulted in a sample size of 2293 women. The assumption was that after three years (2013-2015) of implementation, skilled deliveries would have increased from 38 to $58 \%, 62$ to $72 \%$ and 68 to $78 \%$ in the intervention area of Kibuku, Pallisa and Kamuli districts respectively. For the purpose of this study, the data sets for the two project study areas were pooled. However, to verify if the sample size was good enough to measure neonatal death risk factors, we re-estimated the sample size using openEpi [21] at 95\% confidence interval with an expected newborn death rate of $27 / 1000$, a precision of 9/1000 (27/1000 $\pm 9 / 1000)$ and a 1.5 design effect which gave us sample size 1867 women. The sample size was, therefore, sufficient to measure newborn death rate and its related predictors.

To select 2293 women, we created a sampling frame of all villages in each of the study areas and estimated 199 villages required to realize the calculated sample size based on an annual average of at least 12 newly delivered women in each village. The 199 villages were selected based on probability proportionate to size. Thereafter, we listed all households in order to identify women who had delivered in the last 12 months irrespective of the birth outcome. During listing, 1946 women were identified as eligible women and all considered for interviews since the estimated sample size was not realized. Trained research assistants made home visits and used a structured questionnaire to interview all eligible women (Additional file 1). The questionnaire was in local language. The principle investigators (RMK, SNK, EEK and MT) and supervisors checked the data collected each day while in the field for completeness. Women whose pregnancies were terminated before 20 weeks were not included. The questionnaires included items for socio-demographic characteristics, antenatal care, socio-economic factors, birth outcome, health system factors, and cultural factors. During analysis, we excluded 52 stillbirths since our focus was on the factors affecting the newborn deaths within 28 days after delivery.

\section{Study variables}

In this study, there were four simultaneous equations having at least one endogenous variable as independent variables in each of the equations. The four interrelated study outcomes (endogenous variables) were newborn death, $\mathrm{LBW}$, at least four ANC visits, and health facility delivery. On the other hand, the exogenous factors were the history of newborn death, receiving VHT home visits, ANC first trimester attendance, gestational age, saving for maternal health, and other socio-demographic characteristics such as religion, occupation, marital status, education, age, gravida, and transport to the health facility.

\section{Data analysis}

We analyzed data using STATA 13.0 in three stages. Firstly, we did a descriptive summary of socio-demographic characteristics, health facility delivery, ANC attendance, newborn death, LBW, and other selected variables. Secondly, we performed a bivariate analysis using ulogit STATA command in order to attain the likelihood of the predictors of maternal health utilization and newborn outcomes. Thirdly, we used a generalized structural equation modeling multivariate approach with binomial logit link function since the study had more than one endogenous variable [22]. Only variables that were significant at bivariate analysis and those that were indicated by Marsh et al., 2002 as well as Mosley \& Chen frameworks $[6,23]$ as potential determinants of maternal health utilization and newborn health outcomes were included in the multivariate analysis. We used pairwise correlation matrix to determine the correlation between the independent variables and likelihood ratio test to test for model goodness of fit.

\section{Results \\ Description of study participants}

Table 1 presents the description of 1894 mothers of newborns. The majority (92\%) of participants were peasants, more than a half $(62 \%)$ of the respondents had not attained any education and most (91\%) were married. In addition, the motorcycle was the most common means of transport used to the health facility (66\%) and followed by foot/bicycle (20\%). Additionally, $15 \%$ were teenage mothers and $14 \%$ were of the age 35 and above. Furthermore, 33 per 1000 live births (63/1894) were newborns delivered at the gestational age of 5-7 months and almost two out of five (787/1894) respondents had at least five pregnancies. Fifty-seven per a thousand (109/1894) women had ever experienced a newborn death, 28\% (530/1894) had ever received VHT visit after delivery and $35.7 \%(676 / 1894)$ had ever received VHT visit while pregnant. Additionally, 31\% (596/1894) 
Table 1 Distribution by socio-demographic/economic and health characteristics

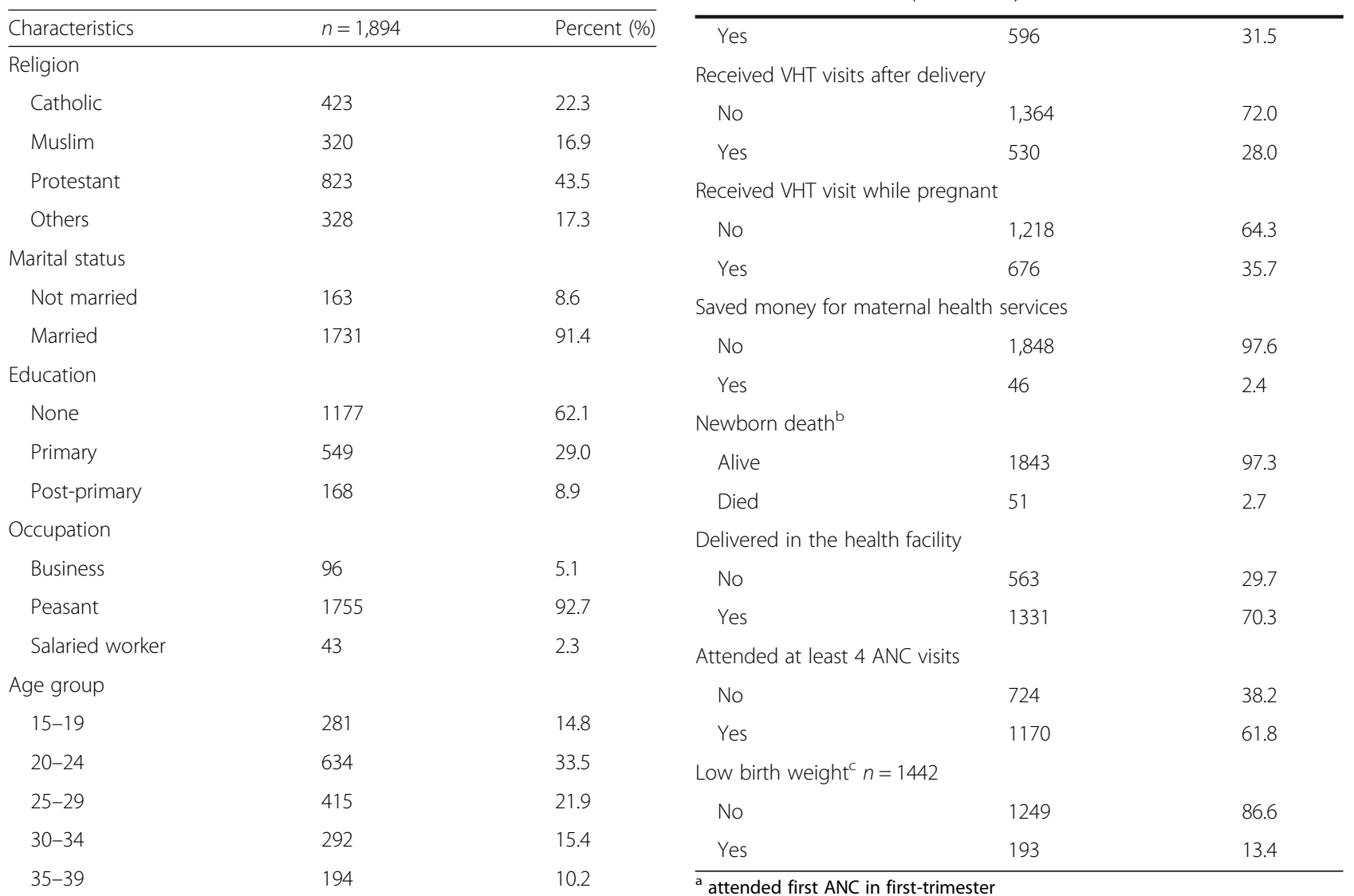

$40+$

Gestational age at birth

$\begin{array}{lll}\text { 5-6Months } & 21 & 1.1 \\ \text { 7Months } & 42 & 2.2 \\ \text { 8Months } & 271 & 14.3 \\ \text { 9Months } & 1560 & 82.4\end{array}$

Gravida

One 306

two 296

Three 284

Four 221

Five and above $\quad 787$

Type of transport used to the facility

Motorcycle 1,245

Vehicle 274

Others 375

Had a history of newborn death

No

Attended ANC Early ${ }^{a}$

Table 1 Distribution by socio-demographic/economic and

health characteristics (Continued)
Received VHT visits after delivery

Received VHT visit while pregnant

Saved money for maternal health services

${ }^{b}$ died within 28 days after birth

accessed ANC in their first trimester and only two services.

Health facility utilization and newborn health outcomes Seven out of ten (1331/1894) respondents delivered in the health facility and almost four out of ten (724/1894) did not attend all the four ANC visits. Low birth weight was found among 13.4\% (193/1442) babies; however, $24 \%(452 / 1894)$ of the newborns were not weighed. Newborn death was estimated to be 27 per 1,000 (51/ 1894) live births with the majority (83\%) dying within seven days after birth. In addition, 33 out of 51 newborn deaths $(68 \%)$ happened within one day $(24 \mathrm{~h})$.

Maternal health utilization and newborn health predictors at bivariate level

Bivariate analysis was conducted for study variables that had the possibility of being predictors of health facility utilization in the multivariate analysis. Table 2 shows the variable relationships. Factors that significantly increased the odds of health facility delivery were being a salaried worker compared to those that had petty businesses, at percent $(46 / 1894)$ had saved money for maternal health 
Table 2 Differentials in maternal health utilization by socio-demographic factors and health facility utilization

\begin{tabular}{|c|c|c|c|c|}
\hline & Health facility delivery & ANC four-time attendance & Newborn death & Low birth weight \\
\hline & Unadjusted OR (95\%Cl) & Unadjusted OR (95\%Cl) & Unadjusted OR (95\% Cl) & Unadjusted OR (95\% Cl) \\
\hline \multicolumn{5}{|l|}{ Religion } \\
\hline Catholic $^{a}$ & 1.00 & 1.00 & 1.00 & 1.00 \\
\hline Muslim & $0.80(0.62-1.03)$ & $0.87(0.68-1.11)$ & $1.44(0.68-3.05)$ & $1.04(0.81-1.33)$ \\
\hline Protestant & $1.04(0.86-1.27)$ & $1.03(0.85-1.24)$ & $0.62(0.32-1.21)$ & $1.11(0.92-1.34)$ \\
\hline Others & $1.10(0.85-1.44)$ & $0.88(0.69-1.13)$ & $1.86(0.92-3.76)$ & $0.91(0.71-1.18)$ \\
\hline \multicolumn{5}{|l|}{ Marital status } \\
\hline No married ${ }^{\mathrm{a}}$ & 1.00 & 1.00 & 1.00 & 1.00 \\
\hline Married & $0.95(0.67-1.36)$ & $1.24(0.90-1.72)$ & $0.65(0.25-1.69)$ & $0.81(0.58-1.12)$ \\
\hline \multicolumn{5}{|l|}{ Education } \\
\hline None $^{a}$ & 1.00 & 1.00 & 1.00 & 1.00 \\
\hline Primary & $1.25(0.87-1.80)$ & $1.34(0.96-1.88)$ & $1.48(0.57-3.84)$ & $0.63(0.44-0.90)^{*}$ \\
\hline Post primary & $1.22(0.98-1.53)$ & $1.15(0.94-1.41)$ & $0.34(0.13-0.88)^{*}$ & $0.75(0.61-0.93)^{*}$ \\
\hline \multicolumn{5}{|l|}{ Occupation } \\
\hline Business $^{a}$ & 1.00 & 1.00 & 1.00 & 1.00 \\
\hline Peasant & $0.88(0.60-1.30)$ & $0.90(0.63-1.29)$ & $0.44(0.18-1.06)$ & $1.27(0.88-1.85)$ \\
\hline Salaried worker & $2.65(1.11-6.33)^{*}$ & $1.82(0.91-3.64)$ & $2.33(0.54-9.97)$ & $0.23(0.09-0.59)^{*}$ \\
\hline \multicolumn{5}{|l|}{ Age group } \\
\hline $15-19^{a}$ & 1.00 & 1.00 & 1.00 & 1.00 \\
\hline $20-24$ & $0.94(0.75-1.17)$ & $1.21(0.98-1.51)$ & $0.61(0.27-1.38)$ & $0.98(0.69-1.39)$ \\
\hline $25-29$ & $0.91(0.71-1.15)$ & $1.21(0.97-1.52)$ & $0.62(0.26-1.50)$ & $0.40(0.25-0.64)^{*}$ \\
\hline $30-34$ & $0.98(0.74-1.28)$ & $1.01(0.78-1.31)$ & $0.97(0.40-2.33)$ & $0.99(0.65-1.50)$ \\
\hline $35-39$ & $1.41(0.99-1.99)$ & $0.69(0.51-0.93)^{*}$ & $1.26(0.49-3.25)$ & $1.04(0.64-1.70)$ \\
\hline $40+$ & $0.79(0.49-1.27)$ & $0.61(0.38-0.95)^{*}$ & $0.59(0.08-4.36)$ & $1.04(0.48-2.22)$ \\
\hline \multicolumn{5}{|c|}{ Had a history of newborn death } \\
\hline $\mathrm{No}^{\mathrm{a}}$ & 1.00 & 1.00 & 1.00 & 1.00 \\
\hline Yes & $1.02(0.67-1.56)$ & $0.81(0.55-1.19)$ & $12.62(6.49-24.57)^{*}$ & $1.38(0.93-2.04)$ \\
\hline \multicolumn{5}{|c|}{ Attended at least 4 ANC visits } \\
\hline $\mathrm{No}^{\mathrm{a}}$ & 1.00 & - & 1.00 & 1.00 \\
\hline Yes & $1.42(1.17-1.75)^{*}$ & - & $0.83(0.44-1.57)$ & $0.62(0.45-0.84)^{*}$ \\
\hline \multicolumn{5}{|l|}{ Attended ANC Early } \\
\hline $\mathrm{No}^{\mathrm{a}}$ & 1.00 & 1.00 & 1.00 & 1.00 \\
\hline Yes & $0.95(0.77-1.17)$ & $3.27(2.61-4.10)^{*}$ & $0.54(0.25-1.18)$ & $0.88(0.64-1.24)$ \\
\hline \multicolumn{5}{|c|}{ Received VHT visit while pregnant } \\
\hline $\mathrm{No}^{\mathrm{a}}$ & 1.00 & 1.00 & - & 1.00 \\
\hline Yes & $1.31(1.06-1.61)^{*}$ & $1.27(1.05-1.55)^{*}$ & - & $1.03(0.76-1.42)$ \\
\hline \multicolumn{5}{|c|}{ Saved for money maternal health services } \\
\hline $\mathrm{No}^{\mathrm{a}}$ & 1.00 & 1.00 & - & - \\
\hline Yes & $1.77(1.18-2.64)^{*}$ & $1.04(0.71-1.40)$ & - & - \\
\hline \multicolumn{5}{|l|}{ Gravida } \\
\hline One $e^{a}$ & 1.00 & 1.00 & 1.00 & 1.00 \\
\hline Two & $0.86(0.60-1.24)$ & $0.98(0.70-1.36)$ & $1.15(0.50-2.62)$ & $1.1(0.85-1.43)$ \\
\hline Three & $0.74(0.51-1.06)$ & $1.03(0.74-1.44)$ & $0.81(0.31-2.08)$ & $0.8(0.61-1.05)$ \\
\hline Four & $0.84(0.57-1.25)$ & $1.31(0.91-1.89)$ & $0.84(0.30-2.38)$ & $1.06(0.79-1.42)$ \\
\hline
\end{tabular}


Table 2 Differentials in maternal health utilization by socio-demographic factors and health facility utilization (Continued)

\begin{tabular}{|c|c|c|c|c|}
\hline Five and above & $0.72(0.53-0.97)^{*}$ & $0.84(0.64-1.11)$ & $0.75(0.39-1.45)$ & $1.1(0.91-1.33)$ \\
\hline \multicolumn{5}{|c|}{ Gestational age at birth } \\
\hline 5-6Months & - & - & $12.01(3.85-37.47)^{*}$ & - \\
\hline 7Months ${ }^{a}$ & - & - & 1.00 & - \\
\hline 8Months & - & - & $0.66(0.23-1.87)$ & - \\
\hline 9Mmonths & - & - & $0.43(0.22-0.85)^{*}$ & - \\
\hline \multicolumn{5}{|c|}{ Type of Transport used to the health facility } \\
\hline Motorcycle ${ }^{a}$ & - & - & 1.00 & - \\
\hline Vehicle & - & - & $2.07(1.09-3.94)^{*}$ & - \\
\hline foot/bicycle & - & - & $1.25(0.65-2.42)$ & - \\
\hline \multicolumn{5}{|l|}{ Low birth weight } \\
\hline $\mathrm{No}^{\mathrm{a}}$ & & & 1.00 & - \\
\hline Yes & & & $5.56(2.70-11.44)$ & - \\
\hline \multicolumn{5}{|c|}{ Delivered in the health facility } \\
\hline $\mathrm{No}^{\mathrm{a}}$ & - & - & 1.00 & - \\
\hline Yes & - & - & $1.28(0.62-2.63)$ & - \\
\hline \multicolumn{5}{|c|}{ Received VHT visits after delivery } \\
\hline $\mathrm{No}^{\mathrm{a}}$ & - & - & 1.00 & - \\
\hline Yes & - & - & $0.45(0.2-1.07)$ & - \\
\hline \multicolumn{5}{|c|}{ Baby experienced danger signs } \\
\hline $\mathrm{No}^{\mathrm{a}}$ & - & - & 1.00 & \\
\hline Yes & - & - & $0.87(0.45-1.68)$ & \\
\hline \multicolumn{5}{|c|}{ Mother experienced danger signs } \\
\hline $\mathrm{No}^{\mathrm{a}}$ & - & - & 1.00 & - \\
\hline Yes & - & - & $1.22(0.65-2.29)$ & - \\
\hline
\end{tabular}

OR-Odds Ratio, ${ }^{*} p<0.05,{ }^{\text {a }}$ reference category, dash (-) denotes variables not considered for particular outcome

least four ANC visits, VHTs visits during pregnancy and saving money for maternal services $(p<0.05)$. The odds of health facility delivery was significantly reduced by being gravida $5+$ compared to being gravida one $(p<0.05)$. Regarding the recommended ANC attendance, factors that significantly increased the probability of at least four ANC visits were attendance of ANC in the first trimester, and VHTs visits during pregnancy $(p<0.05)$. Furthermore, factors that significantly reduced the probability of having at least four ANC visits were belonging to the age group of $35+$ years compared to the age group $14-19$ years $(p<0.05)$.

Regarding newborn health outcomes, factors that significantly reduced the odds of neonatal death were post primary education completion compared to none and gestational age of eight months to nine months compared to the gestational age of 7 months $(p<0.05)$. In addition, factors that increased the odds of newborn death were the history of newborn death, LBW, gestational age at the time of birth of 5-6 months compared to the gestational age of 7 months and use of motor vehicle transport compared to the motorcycle $(p<0.05)$.
Factors that significantly reduced the odds of LBW were at least four ANC visits, having at least primary education level compared to none and a salaried occupation compared to petty business.

The predictors of newborn death, LBW, health facility delivery and at least four ANC visits at bivariate level do not reveal causal linkages between the variables. Therefore, a structural equation modeling approach was used to understand the causal linkages as indicated in the next results-sub section. All significant variables identified in the bivariate analysis were considered for further analysis in the multivariate model. However, variables that were not significant such as age group, gravida, education, and occupation were controlled for in the multivariate analysis since available literature has indicated their contribution towards newborn death, low birth weight, and health facility utilization.

\section{The interrelationship between health facility utilization and newborn health outcomes}

Table 3 indicates the details of the interrelationship between health facility utilization and newborn health 
Table 3 Analysis of interrelationship between maternal health utilization and newborn health outcomes using GSEM

\begin{tabular}{|c|c|c|c|c|}
\hline & \multicolumn{2}{|c|}{ Newborn Outcome indicators } & \multicolumn{2}{|l|}{ Facility utilization indicators } \\
\hline & Newborn death $\left(Y_{1}\right)$ & Low birth weight $\left(\mathrm{Y}_{2}\right)$ & Health facility delivery $\left(Y_{3}\right)$ & ANC 4 time attendance $\left(\mathrm{Y}_{4}\right)$ \\
\hline & \multicolumn{2}{|l|}{ Adjusted OR (95\% Cl) } & \multicolumn{2}{|l|}{ Adjusted OR (95\% Cl) } \\
\hline \multicolumn{5}{|c|}{ Delivered in the health facility } \\
\hline $\mathrm{No}^{\mathrm{a}}$ & 1.00 & - & - & - \\
\hline Yes & $0.47(0.19-1.26)$ & - & - & - \\
\hline \multicolumn{5}{|c|}{ Attended at least 4 ANC visits } \\
\hline $\mathrm{No}^{\mathrm{a}}$ & - & 1.00 & 1.00 & - \\
\hline Yes & - & $0.62(0.45-0.85)^{* *}$ & $1.43(1.16-1.75)^{* *}$ & - \\
\hline \multicolumn{5}{|l|}{ Age group } \\
\hline $15-19^{a}$ & & 1.00 & 1.00 & 1.00 \\
\hline $20-24$ & & $0.24(0.08-0.73)^{*}$ & $1.04(0.76-1.42)$ & $1.17(0.97-1.40)$ \\
\hline $25-29$ & & $0.20(0.05-0.86)^{*}$ & $0.93(0.66-1.30)$ & $1.20(0.98-1.47)$ \\
\hline $30-35$ & & $0.34(0.10-1.17)$ & $1.01(0.70-1.45)$ & $1.13(0.91-1.41)$ \\
\hline $34-59$ & & $0.40(0.11-1.42)$ & $1.27(0.86-1.86)$ & $0.91(0.73-1.13)$ \\
\hline \multicolumn{5}{|l|}{ Attended ANC Early } \\
\hline $\mathrm{No}^{\mathrm{a}}$ & - & - & - & 1.00 \\
\hline Yes & - & - & - & $2.04(1.79-2.34)^{* *}$ \\
\hline \multicolumn{5}{|c|}{ Received VHT visit while pregnant } \\
\hline $\mathrm{No}^{\mathrm{a}}$ & - & - & - & 1.00 \\
\hline Yes & - & - & - & $1.14(1.01-1.30)^{*}$ \\
\hline \multicolumn{5}{|l|}{ Marital status } \\
\hline Not Married ${ }^{a}$ & 1.00 & 1.00 & 1.00 & 1.00 \\
\hline Married & $0.77(0.23-2.60)$ & $0.90(0.53-1.53)$ & $0.94[0.65,1.36]$ & $1.15[0.93-1.41]$ \\
\hline \multicolumn{5}{|l|}{ Education Level } \\
\hline None $^{a}$ & - & 1.00 & 1.00 & 1.00 \\
\hline Primary & - & $0.75(0.38-1.45)$ & $1.15(0.76-1.72)$ & $1.18(0.92-1.50)$ \\
\hline Post primary & - & $0.68(0.46-0.98)^{*}$ & $1.29(1.02-1.63)^{*}$ & $1.11(0.97-1.27)$ \\
\hline \multicolumn{5}{|l|}{ Occupation } \\
\hline Business $^{a}$ & 1.00 & 1.00 & 1.00 & 1.00 \\
\hline Peasant & $0.54(0.11-2.65)$ & $0.85(0.40-1.79)$ & $1.26(0.80-1.97)$ & $1.14(0.87-1.49)$ \\
\hline Salaried worker & $0.42(0.04-4.60)$ & $1.07(0.29-3.88)$ & $2.84(1.03-7.80)^{*}$ & $1.50(0.88-2.53)$ \\
\hline \multicolumn{5}{|c|}{ Had a history of newborn death } \\
\hline $\mathrm{No}^{\mathrm{a}}$ & 1.00 & 1.00 & - & - \\
\hline Yes & $12.64(5.31-30.10)^{* *}$ & $1.33(0.72-2.47)$ & - & - \\
\hline \multicolumn{5}{|l|}{ Gravida } \\
\hline One ${ }^{a}$ & - & 1.00 & - & - \\
\hline two & - & $0.91(0.53-1.54)$ & - & - \\
\hline Three & - & $0.49(0.26-0.94)^{*}$ & - & - \\
\hline Four & - & $0.65(0.31-1.37)$ & - & - \\
\hline Five and above & - & $0.79(0.39-1.60)$ & - & - \\
\hline \multicolumn{5}{|c|}{ Type of Transport used to the facility } \\
\hline Motorcycle ${ }^{a}$ & 1.00 & - & - & - \\
\hline Vehicle & $0.79(0.20-3.16)$ & - & - & - \\
\hline Foot/bicycle & $1.40(0.49-3.93)$ & - & - & - \\
\hline
\end{tabular}


Table 3 Analysis of interrelationship between maternal health utilization and newborn health outcomes using GSEM (Continued)

\begin{tabular}{|c|c|c|c|c|}
\hline \multicolumn{5}{|c|}{ Low Birth Weight } \\
\hline $\mathrm{No}^{\mathrm{a}}$ & 1.00 & - & - & - \\
\hline Yes & $3.51(1.48-8.37)^{* *}$ & - & - & - \\
\hline \multicolumn{5}{|c|}{ Saved money for maternal health services } \\
\hline $\mathrm{No}^{\mathrm{a}}$ & - & - & 1.00 & 1.00 \\
\hline Yes & - & - & $1.72(1.14-2.58)^{* *}$ & $0.92(0.74-1.14)$ \\
\hline
\end{tabular}

OR-Odds Ratio, ${ }^{*} p<0.05,{ }^{* *} p<0.01,{ }^{* * *} p<0.001,{ }^{a}$ reference category, dash (-) denotes variables not considered for particular outcome

outcomes. The direct predictors of newborn death were LBW and history of newborn death, while the indirect factors were at least four ANC visits, education, gravida, ANC first attendance in the first trimester of pregnancy, VHTs visits during pregnancy, and religion. Newborns with low birth weight and those born to mothers with a history of newborn death were more likely to die within 28 days after birth $(\mathrm{aOR}=3.51,95 \% \mathrm{CI} 1.48-8.37)$ and $(\mathrm{aOR}=12.64,95 \%$ CI 5.31-30.10) respectively). The odds of the newborn death was not significantly different between those delivered within and outside of the health facilities.

The factors for LBW as a mediating variable for newborn death were at least four ANC visits, education, gravida, and age. Women who attended ANC at least four times had $38 \%$ reduced odds of delivering low birth weight babies compared to those who attended ANC less than four times
$(\mathrm{aOR}=0.62$, 95\% CI $0.45-0.85)$. Mothers who had postprimary education had $32 \%$ reduced odds of delivering low birth weight babies compared to those who had no education at all $(\mathrm{aOR}=0.68,95 \% \mathrm{CI} 0.46-0.98)$. Mothers who were gravida three had $51 \%$ reduced odds of delivering low birth weight babies compared to those who were gravida one $(\mathrm{aOR}=0.49,95 \% \mathrm{CI}=0.26-0.94)$. LBW was less likely among children born to mothers aged 20-24 $(\mathrm{aOR}=0.24,95 \% \mathrm{CI} 0.07-0.73)$ and $25-$ $29(\mathrm{aOR}=0.20,95 \% \mathrm{CI} 0.05-0.86)$ years compared to those aged 15-19 years. No significant associations identified among women aged above 29 years.

The factors for attending ANC at least four times as a mediating variable for newborn death and LBW were ANC first attendance in the first trimester of pregnancy, VHTs visits during pregnancy and religion (Table 3). Women who attended ANC in the first trimester were

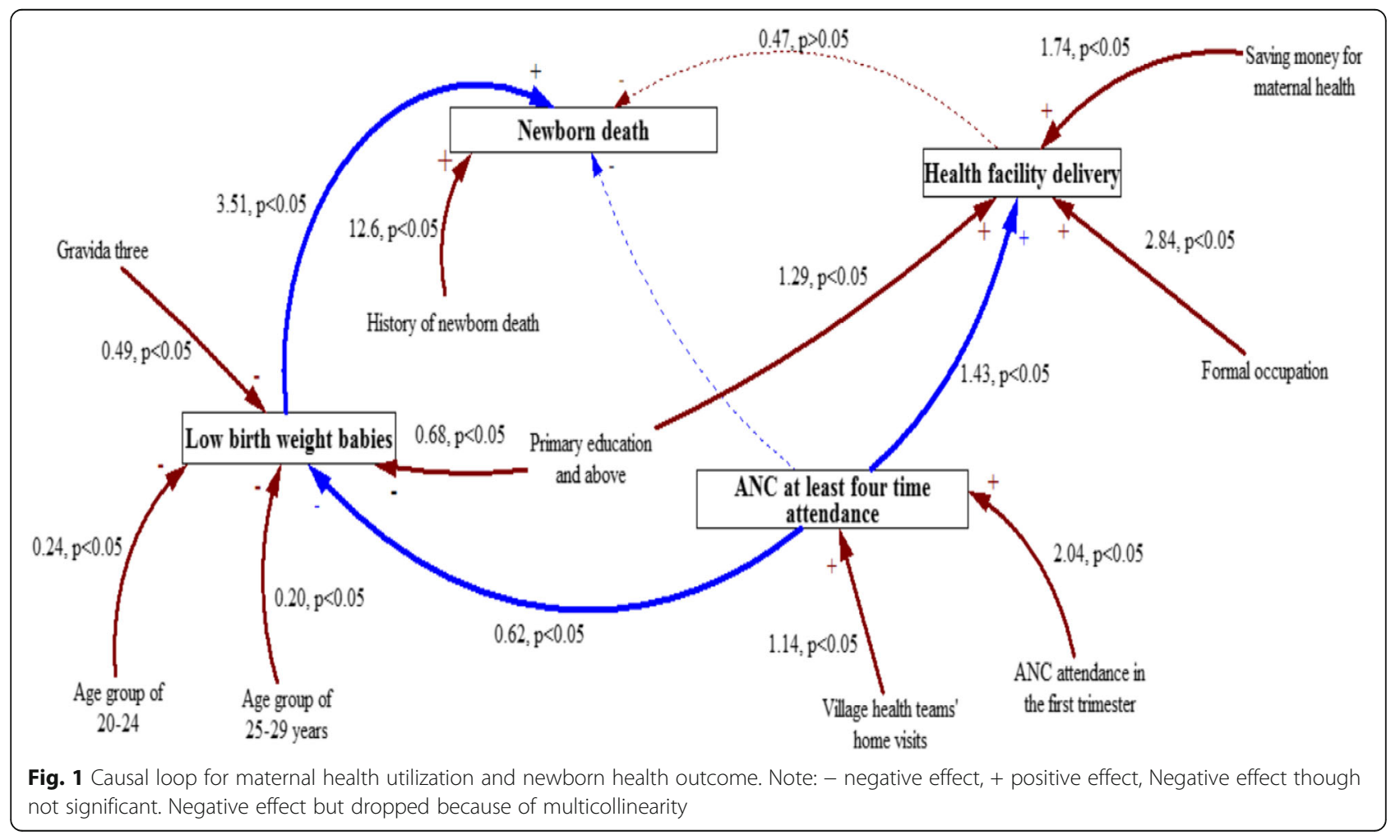


two times more likely to attend $\mathrm{ANC}$ at least four times relative to those who attended ANC in the second trimester or later $(\mathrm{aOR}=2.04,95 \% \mathrm{CI} 1.79-2.34)$. Women who were visited by the VHTs while pregnant had 14\% increased odds of attending ANC at least four times $(\mathrm{aOR}=1.14,95 \%$ CI 1.01-1.30).

Figure 1 is a causal loop diagram that summarizes the interconnectedness between the maternal health care utilization and newborn health outcome factors.

\section{Discussion}

This study has indicated a high proportion of LBW babies in these rural communities and this might be underestimated since almost a quarter of the newborns were not weighed as found in a similar study [11]. Newborn mortality rate was 27 per 1,000 live births, similar to the national average [24]. As noted in similar studies, the newborn mortality rate was high within seven days after delivery $(83 \%)$ with the majority (68\%) of newborns dying within one day $[1,25]$. This is an indication of the critical care needed at the time of birth and the immediate period thereafter for newborns to survive [1]. Newborn deaths in the first seven days are mainly attributed to maternal pregnancy and childbirth related complications and infections [12, 26]. Death occurring within one day might be closely related to community and health facility challenges that include delays in seeking care, poor community transport systems, lack of skilled health workers, lack of equipment and drugs at the health facilities and poor referral networks from the lower level to the higher levels [5].

\section{Interrelationship between newborn outcomes and health utilization factors}

The direct determinants of newborn death were LBW, history of newborn death and mother's age. Since LBW is an endogenous variable, LBW and any other endogenous variable that affect LBW are mediating variables for newborn death. The odds of dying among children born to mothers who had a history of losing newborns was 12 times higher compared to those born by mothers who had no history of newborn death. This was found to be consistent with other studies [24, 27-31]. Other studies have also indicated that women who experienced a pregnancy loss or stillbirth or lost a baby within 28 days in the past are more likely to lose a baby in the subsequent pregnancy $[24,30,31]$. There is, therefore, a need for an examination of historical cohorts of newborns and immediate family members with respect to genetic, chromosomal and congenital predispositions in order to elicit more precise conclusions [32].

The likelihood of increased deaths among LBW newborns was not surprising, since this has been reported in a number of studies done in similar settings [11, 12, 33].
These studies have shown that LBW babies are at a higher risk of a number of health complications, which increase their chances of death if appropriate care is not given. Moreover, the low capacity of health facilities in LMICs to prevent, screen and manage the LBW babies' complications makes it hard for newborns to survive. Therefore, interventions aimed at building the capacity of health workers on how to screen and care for LBW babies at health facilities are vital.

The factors associated with the odds of LBW as a mediating factor for newborn death were education, at least four ANC visits, mother's age, and religion. Post-primary level education of mothers was positively related to the birth weight of newborns; a finding that is consistent with existing studies undertaken in other LMICs [34-36]. Lower education levels have been associated with lower health awareness and health seeking behavior as well as low dietary literacy among mothers, which have been found to have a bearing on LBW [35]. Additionally, LBW among babies born to mothers who were gravida three was found to be lower compared to those whose mothers who were gravida one. Similar studies indicated that mothers who are pregnant for the first time are more likely to deliver LBW than mothers with two to four pregnancies [13, 34, 37]. Furthermore, women aged 20-29 years were less likely to deliver LBW babies compared to women aged 15-19 years and there was no significant association established among mothers aged above 29 years. The increased LBW among children born to mothers aged 15-19 years has been associated with the problems faced by such adolescent mothers, who are often women from vulnerable populations, which predisposes them to less access to care [13, 34, 37, 38]. Poor knowledge levels and nutrition status coupled with underdeveloped reproductive organs further increase the chances of adolescents to deliver LBW babies [36]. Additionally, the increased odds of LBW among elderly mothers might be related to poor child spacing [36].

Regarding attending ANC at least four times as a mediating factor for LBW and newborn death, newborns whose mothers attended ANC at least four times were less likely to be LBW babies compared to those who attended for less times, which was consistent with other studies [12, 34, 37]. The World Health Organization (WHO) recommends a minimum of four antenatal visits during pregnancy since this is a period when newborns are affected by problems such as preterm birth, restricted fetal growth and congenital infections that might increase the chances of newborn death [39]. Furthermore, attending ANC has been indicated as a potential avenue for women and their families to receive information and advice on obstetric care as well as identification and management of infections such as Malaria, HIV/ AIDS, Syphilis, and other sexually transmitted diseases 
[39] that have an effect on the fetus. This confirms the importance of conducting population-oriented programs that encourage early ANC attendance [37].

In this study, women who attended ANC in the first trimester had two times the odds of attending ANC at least four times relative to those who attended ANC in the second trimester and above, which was in agreement with a study done in Malawi and Ghana [40]. In addition, the odds of at least four ANC visits was higher among women visited by VHTs while pregnant. This confirms the importance of community health workers in promoting maternal service utilization particularly in rural communities as reported in other studies done in Sub-Saharan Africa [5, 39, 41-45]. These studies have highlighted the importance of community health workers in identifying pregnant women in the community, sensitizing, encouraging and empowering them to seek maternal health services from a qualified health worker. Home visits by VHTs encourages women to attend ANC early (in the first trimester), which helps them benefit fully from preventive strategies, such as iron and folic acid supplementation, treatment of helminthic infections, and intermittent preventive treatment with sulfadoxine-pyrimethamine for malaria in pregnancy among other interventions [39, 46].

Surprisingly, the proportion of newborn deaths for women who delivered in the health facility was not statistically different from those who delivered in the community, which is consistent with recent studies in similar settings $[11,12]$. This indifference has been linked to the poor quality of care in the health facilities as well as the possibility of births happening in health facilities but without skilled personnel assistance [33, 47]. This is made worse by system-wide challenges such as drugs and supplies shortages, the lack of essential equipment and shortage of health workers exemplified by a similar study done in Eastern Uganda [48]. This therefore indicates that increasing health facility deliveries without addressing supply side constraints is unlikely to reduce the newborn mortality. In fact, poor quality services at the health facilities reduce utilization of maternal and newborn services. Interventions seeking to improve neonatal health outcomes, therefore, need to consider tackling both demand and supply side constraints.

\section{Limitations of the study}

The analysis was limited to the available information on variables given the nature of the dataset. In addition, the results are generalizable to communities in rural Eastern Uganda but can also be generalized to areas that have a similar context. Additionally, recall bias might have affected the study results but we minimized this by including only women who had delivered in the last 12 months. In addition, excluding 52 records of stillbirth might have had an effect on the health facility and ANC four-time attendance outcomes, however, the records were less than $3 \%$ of the total number of participants. The study also did not assess causes of death by timing.

\section{Conclusions}

The interdependence between the predictors of maternal health care utilization and newborn health outcomes highlight important areas of focus for interventions aimed at reducing neonatal mortality. Community health interventions such as home visits by village health teams should be strengthened in order to improve early ANC attendance and recommended ANC visits. There is a need to target women with high risk pregnancies in particular those with a previous history of neonatal mortality and teenage pregnancy. In addition, low cost interventions that improve identification and survival of low birth weight babies in low resource settings should be strengthened.

\section{Additional file}

Additional file 1: Household survey data collection tool. (PDF 930 kb)

\section{Abbreviations}

ANC: Antenatal Care; IRB: Institutional Review Board; LBW: Low birth weight; MakSph: Makerere University School of Public Health; MCHCU: Maternal Health Care Utilization; UDHS: Uganda Demographic Health Survey; UNCST: Uganda National Council for Science and Technology; VHTs: Village Health Teams; WHO: World Health Organization

\section{Acknowledgements}

We are thankful to the study participants and the district health office from the districts of Kamuli, Kibuku and Pallisa for their time during data collection. We are grateful to Future Health System and Makerere University School of Public Health for their technical support during the design and the implementation of this study.

\section{Funding}

The MANIFEST study was funded by Comic Relief grant code 112483. The funding body did not play any direct role in the study data collection, analysis and writing of the manuscript. The content is solely the responsibility of the authors and does not necessarily represent the official views of Comic Relief.

\section{Availability of data and materials}

The dataset generated and analyzed in this study is available from the corresponding author on reasonable request.

\section{Authors' contributions \\ RMK carried out data collection, analysis and led the writing of the manuscript with the contribution from all authors. RW participated in conceiving and reviewing the study, EE-K provided general guidance and participated in drafting and reviewing the manuscript, MT, SNK and PW participated in reviewing the study, and LKA provided guidance in data analysis and presentation.}

\section{Competing interests}

The authors declare that they have no competing interests.

\section{Consent for publication}

Not applicable

Ethics approval and consent to participate

We analyzed the end-line household survey dataset for MANIFEST project that was implemented in Eastern Uganda. The MANIFEST principal investigators 
obtained ethical approval from Makerere University School of Public Health (MakSph) institutional review board (IRB) reference number HDREC 152 and Uganda National Council for Science and Technology (UNCST) reference number HS 1399. Each individual study participant signed a translated consent form upon consenting to take part in the evaluation study.

\section{Publisher's Note}

Springer Nature remains neutral with regard to jurisdictional claims in published maps and institutional affiliations.

\section{Author details}

'Makerere University School of Public Health (MakSPH), Makerere University College of Health Sciences, Kampala, Uganda. ${ }^{2}$ Department of Planning and Applied Statistics, Makerere University School of Statistics and Planning, Kampala, Uganda. ${ }^{3}$ Epidemiology and Global Health Unit, Department of Public Health and Clinical Medicine, Umeå University, Umeå, Sweden. ${ }^{4} G l o b a l$ Health Division, Department of Public Health Sciences, Karolinska Institutet, Stockholm, Sweden. ${ }^{5}$ Maternal and Newborn Centre of Excellence, Makerere University School of Public Health, Kampala, Uganda.

\section{Received: 22 September 2016 Accepted: 23 March 2017}

\section{Published online: 27 March 2017}

\section{References}

1. Lawn JE, Cousens S, Zupan J. 4 Million neonatal deaths: When? Where? Why? Lancet. 2005;365:891-900.

2. UNICEF. The State of the World's Children 2014 -Every Child Counts. New York; 2014. http://www.unicef.org/sowc2014/numbers/documents/english/ SOWC2014_In Numbers_28 Jan.pdf.

3. Ayele DZ, Belayihun B, Teji K, Ayana DA. Factors affecting utilization of maternal health care services in Kombolcha District, Eastern Hararghe Zone, Oromia Regional State, Eastern Ethiopia. Int Sch Res Not. 2014;2014:7.

4. Kinney MV, Kerber KJ, Black RE, Cohen B, Nkrumah F, Coovadia H, et al. Sub-Saharan Africa's mothers, newborns, and children: Where and why do they die? PLoS Med. 2010;7:1-9.

5. Waiswa P, Kallander K, Peterson S, Tomson G, Pariyo GW. Using the three delays model to understand why newborn babies die in eastern Uganda. Trop Med Int Heal. 2010;15:964-72. doi:10.1111/j.1365-3156.2010.02557.x.

6. Marsh DR, Darmstadt GL, Moore J, Daly P, Oot D, Tinker A. Advancing newborn health and survival in developing countries: a conceptual framework. J Perinatol. 2002;22:572-6.

7. Chou D, Daelmans B, Jolivet RR, Kinney M, Say L. Ending preventable maternal and newborn mortality and stillbirths. Bmj. 2015; h4255. doi:10. 1136/bmj.h4255.

8. Penfold S, Shamba D, Hanson C, Jaribu J, Manzi F, Marchant T, et al. Staff experiences of providing maternity services in rural southern Tanzania - a focus on equipment, drug and supply issues. BMC Health Serv Res. 2013;13: 61. doi:10.1186/1472-6963-13-61.

9. Dogba M, Fournier P. Human resources and the quality of emergency obstetric care in developing countries: a systematic review of the literature. Hum Resour Health. 2009;7:7. doi:10.1186/1478-4491-7-7.

10. Namiiro FB, Mugalu J, McAdams RM, Ndeezi G. Poor birth weight recovery among low birth weight/preterm infants following hospital discharge in Kampala, Uganda. BMC Pregnancy Childbirth. 2012;12:1.

11. Kananura RM, Tetui M, Mutebi A, Bua JN, Waiswa P, Kiwanuka SN, et al. The neonatal mortality and its determinants in rural communities of Eastern Uganda. Reprod Health. 2016;1-9. doi:10.1186/s12978-016-0119-y.

12. Kassar SB, Melo AMC, Coutinho SB, Lima MC, Lira PIC. Determinants of neonatal death with emphasis on health care during pregnancy, childbirth and reproductive history. J Pediatr (Rio J). 2013;89:269-77.

13. Ministry of Health Uganda and ORC Macro. Uganda Demographic and Health Survey 2011. 2011. http://ubos.org/onlinefiles/uploads/ubos/pdf documents/Uganda DHS 1988-89 Final Report.pdf.

14. Chi PC, Bulage P, Urdal H, Sundby J. A qualitative study exploring the determinants of maternal health service uptake in post-conflict Burundi and Northern Uganda. BMC Pregnancy Childbirth. 2015;15:18. doi:10.1186/ s12884-015-0449-8

15. Amoakoh-Coleman M, Ansah EK, Agyepong IA, Grobbee DE, Kayode GA Klipstein-Grobusch K. Predictors of skilled attendance at delivery among antenatal clinic attendants in Ghana: a cross-sectional study of population data. BMJ Open. 2015;5:e007810. doi:10.1136/bmjopen-2015-007810.
16. Joharifard S, Rulisa S, Niyonkuru F, Weinhold A, Sayinzoga F, Wilkinson J, et al. Prevalence and predictors of giving birth in health facilities in Bugesera District, Rwanda. BMC Public Health. 2012;12:1049. doi:10.1186/ 1471-2458-12-1049.

17. Anyait A, Mukanga D, Oundo GB, Nuwaha F. Predictors for health facility delivery in Busia district of Uganda: a cross sectional study. BMC Pregnancy Childbirth. 2012;12:132. doi:10.1186/1471-2393-12-132.

18. Kiwanuka SN, Ekirapa EK, Peterson S, Okui O, Rahman MH, Peters D, et al. Access to and utilisation of health services for the poor in Uganda: a systematic review of available evidence. Trans R Soc Trop Med Hyg. 2008; 102:1067-74. doi:10.1016/j.trstmh.2008.04.023.

19. Christiana RT, Michael JD, Kingsley A, Christine LR, Hall J. Determinants of neonatal mortality in Indonesia. BMC Public Health. 2008:8:232.

20. UBOS. Uganda Bureau of Statistics; 2014 Statistical Abstract. 2014.

21. Dean A, Sullivan K, Soe M. OpenEpi: Open Source Epidemiologic Statistics for Public Health. Updat 2011/23/06. 2011;:Version 2.3.1. www.OpenEpi.com.

22. Huber C. Generalized Structural Equation Modeling Using Stata. 2013.

23. Mosley $\mathrm{WH}$, Chen LC. An analytical framework for the study of child survival in developing countries. 1984. Bull World Health Organ. 2003;81:140-5. http://www.pubmedcentral.nih.gov/articlerender.fcgi?artid=2572391\&tool= pmcentrez\&rendertype=abstract.

24. Getahun D, Lawrence JM, Fassett MJ, Strickland D, Koebnick C, Chen W, et al. The association between stillbirth in the first pregnancy and subsequent adverse perinatal outcomes. Am J Obstet Gynecol. 2009;201:378-80. doi:10. 1016/j.ajog.2009.06.071.

25. Rammohan A, lqbal K, Awofeso N. Reducing Neonatal Mortality in India: Critical Role of Access to Emergency Obstetric Care. PLoS One. 2013:8:3.

26. Pedrosa LDCO, Sarinho SW, Ordonha MR. Quality of information analysis on basic causes of neonatal deaths recorded in the Mortality Information System: a study in Maceió, Alagoas State, Brazil, 2001-2002. Cad Saude Publica. 2007;23:2385-95

27. van Dinter MC, Graves L. Managing adverse birth outcomes: helping parents and families cope. Am Fam Physician. 2012;85:900-4.

28. Turton P, Hughes P, Evans CD, Fainman D. Incidence, correlates and predictors of post-traumatic stress disorder in the pregnancy after stillbirth. Br J Psychiatry. 2001:178:556-60. doi:10.1192/bjp.178.6.556.

29. August EM, Salihu HM, Weldeselasse H, Biroscak BJ, Mbah AK, Alio AP. Infant mortality and subsequent risk of stillbirth: a retrospective cohort study. BJOG. 2011;118:1636-45.

30. Mahande MJ, Daltveit AK, Mmbaga BT, Obure J, Masenga G, Manongi R, et al. Recurrence of perinatal death in Northern Tanzania: a registry based cohort study. BMC Pregnancy Childbirth. 2013;13:166. doi:10.1186/ 1471-2393-13-166.

31. Reddy Uma M, Katherine Laughon S, Liping $S$, James $T$, Willinger M, Jun Z Prepregnancy risk factors for Antepartum stillbirth in the United States. Obstet Gynecol. 2010;116:1119-26.

32. Williams B, Datta S. Previous fetal death. In: A Textbook of Preconceptional Medicine and Management. 2012. p. 241-50. https://www.glowm.com/ resources/glowm/preconception_pdf/old/Preconceptional\%20MedicineFull. pdf\#page $=149$.

33. Oji S, Odimegwu C. Perinatal mortality in Nigeria: Do place of delivery and delivery assistants matter? Open Demogr J. 2011;4:1-10. https:// benthamopen.com/contents/pdf/TODEMOJ/TODEMOJ-4-1.pdf.

34. Khatun S, Rahman M. Socio-economic determinants of low birth weight in Bangladesh: a multivariate approach. Bangladesh Med Res Counc Bull. 2008;34:81-6.

35. Muula AS, Siziya S, Rudatsikira E. Parity and maternal education are associated with low birth weight in Malawi. Afr Health Sci. 2011;11:65-71.

36. Manna N, Sarkar J, Baur B, Basu G, Bandyopadhyay L. Socio-biological determinants of Low birth weight: a community based study from rural field practice area of medical college, Kolkata, West Bengal (India). losr J Org. 2013;4:33-9. http://www.iosrjournals.org/iosr-jdms/papers/Vol4-issue4/ H0443339.pdf

37. Alemseged A, Mektie W, Semarya B. Maternal risk factors associated with low birth weight. J Coll Physicians Surg Pak. 2003;13:25-8.

38. Ydav D, Chaudhray U, Shrestha N. Maternal risk factors associated with low birth weight. J Nepal Heal Res Counc. 2011;9:159-64.

39. Lincetto O, Mothebesoane-anoh S, Gomez P, Munjanja S. Antenatal Care: Opprotunities for Africa's Newborns. Int J Sci Technol Res. 2013;2:51-62.

40. Pell C, Meñaca A, Were F, Afrah NA, Chatio S, Manda-Taylor $L$, et al. Factors affecting antenatal care attendance: results from qualitative studies in 
Ghana, Kenya and Malawi. PLoS One. 2013;8:e53747. doi:10.1371/journal. pone.0053747.

41. Ediau M, Wanyenze RK, Machingaidze S, Otim G, Olwedo A, Iriso R, et al. Trends in antenatal care attendance and health facility delivery following community and health facility systems strengthening interventions in Northern Uganda. BMC Pregnancy Childbirth. 2013;13: 189. doi:10.1186/1471-2393-13-189.

42. Lema IA, Sando D, Magesa L, Machumi L, Mungure E, Mwanyika Sando M, et al. Community health workers to improve antenatal care and PMTCT uptake in Dar es Salaam, Tanzania: a quantitative performance evaluation. J Acquir Immune Defic Syndr. 2014;67 Suppl 4:S195-201. doi:10.1097/QAI. 0000000000000371.

43. Gogia S, Sachdev HS. Home visits by community health workers to prevent neonatal deaths in developing countries: a systematic review. Bull World Health Organ. 2010:88:658-666B.

44. Gilmore B, McAuliffe E. Effectiveness of community health workers delivering preventive interventions for maternal and child health in low- and middle-income countries: a systematic review. BMC Public Health. 2013;13:847. doi:10.1186/1471-2458-13-847.

45. Aboubaker S, Qazi S, Wolfheim C, Oyegoke A, Bahl R. Community health workers: a crucial role in newborn health care and survival. J Glob Health. 2014:4:1-5. www.ncbi.nlm.nih.gov/pmc/articles/PMC4267086/

46. van Eijk AM, Bles HM, Odhiambo F, Ayisi JG, Blokland IE, Rosen DH, et al. Use of antenatal services and delivery care among women in rural western Kenya: a community based survey. Reprod Health. 2006;3:2.

47. Nathan R, Mwanyangala M. Survival of neonates in rural Southern Tanzania: does place of delivery or continuum of care matter? BMC Pregnancy Childbirth. 2012;12:18. doi:10.1186/1471-2393-12-18.

48. Tetui M, Ekirapa E, Bua J, Mutebi A, Tweheyo R, Waiswa P. Qaulity of Antenatal care services in eastern Uganda: implications for interventions. Pan Afr Med J. 2012;13:1-15. http://www.panafrican-med-journal.com/ content/article/13/27/full/.

\section{Submit your next manuscript to BioMed Central and we will help you at every step:}

- We accept pre-submission inquiries

- Our selector tool helps you to find the most relevant journal

- We provide round the clock customer support

- Convenient online submission

- Thorough peer review

- Inclusion in PubMed and all major indexing services

- Maximum visibility for your research

Submit your manuscript at www.biomedcentral.com/submit

) Biomed Central 